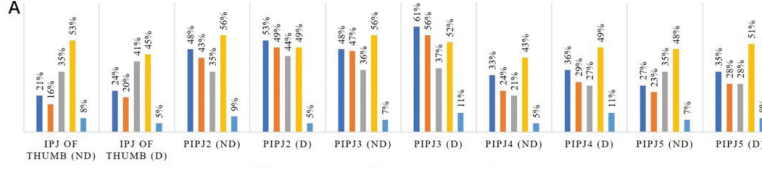
- Joint Tenderness - = Joint Swelling "MRT Tenosynovitis "MRl synovitis $\quad$ "MRl ostetitis

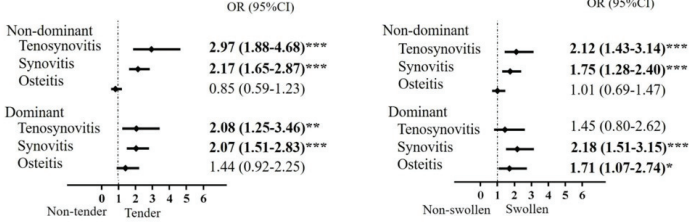

Figure 1 The prevalence and concordance between inflammation detected by MRI and physical examination in various
proximal interphalangeal joints (PIPJs) of early RA patients. A: The prevalence of joint tenderness, joint swelling, MR proximal interphalangeal joints (PIPJs) of early RA patients. A: The prevalence of joint tenderness, joint swelling, MRI
tenosynovitis, synovitis and osteitis per PIPJ. B: Generalized Fstimating Equations with multivariate logistic regression werc tenosynovitis, synovitis and osteitis per PIPJ. B: Generalized Estimating Equations with multivariate logistic regression were
used to show the contribution of MRI tenosynovitis, synovitis and osteitis to joint tenderness or swelling. " $p<0.05$, *** $p<0.01$ used to show

Conclusion: This preliminary study showed MRI-detected digit flexor tenosynovitis in bilateral PIPJs contributed to joint tenderness in early RA patients independently of synovitis which should not be ignored in clinical practice.

Acknowledgement: This work was supported by National Natural Science Foundation of China [grant numbers 81601427 and 81671612), Natural Science Foundation of Guangdong Province [grant numbers 2016A030313307, 2017A030313470 and 2017A030313576], State Scholarship Fund from China Scholarship Council [file number: 201806385034] and Yat-Sen Scholarship for Young Scientists [to Mo YQ]

Disclosure of Interests: None declared

DOI: 10.1136/annrheumdis-2019-eular.4471

\section{FRI0624 U9: A NOVEL CLINICALLY ORIENTED ULTRASONOGRAPHIC SCALE FOR ASSESSING DISEASE ACTIVITY IN RHEUMATOID ARTHRITIS}

Mohammed A. Mortada, Ghada Ghada, Amany Ebaid, Lobna Kotb, Youmna A. Amer. Faculty of Medicine. Zagazig University, Rheumatology and Rehabilitation, Zagazig, Egypt

Background: Musculoskeletal Ultrasonography (MSUS) is now a widely used tool for the monitoring of rheumatoid arthritis (RA). Although there are many proposed sets of composite scores, a fixed set of joints may not be an ideal tool to assess a disease like RA which affects many joints and tendons in different presentations.

Objectives: To assess the correlation of 3 proposed ultrasonographic composite scores with disease activity indices.

Methods: Three different composite scores were proposed by the first author, the first score (modified U8 score) which included bilateral wrists, $2^{\text {nd }} \mathrm{MCP}, 3^{\mathrm{RD}} \mathrm{MCP}$ and knees which of the same set of joints proposed by Yoshimi et al 2015 with a modification of scoring of each joint according to EULAR/OMERACT combined score so the range of scores $(0-24)$. The second score (U9) was the same of the modified U8 score plus scoring the most clinically affected joint or tendon (one joint or one tendon) so the range of score $(0-27)$. The third proposed score $(8+2)$ was the same of the modified U8 score plus scoring the 2 most clinically affected joint or tendon (one joint and one tendon or 2 joints or 2 tendons) so the range of score (0-30). All targeted joints were evaluated by grey-scale (GS) and power Doppler (PD) ultrasound using EULAR/ OMERACT combined score (0-3). Targeted tendons were scored (0-3) by either -scale (GS) and power Doppler (PD) ultrasound and the highest score was used.

One hundred and fifty four RA patients diagnosed according to ACR/ EULAR criteria were recruited for the present study. A total of 154 patients with RA were included. Disease activity was assessed by clinical disease activity indices (CDAI and DAS28 ESR). Functional status was assessed by health assessment questionnaire (HAQ).

Results: In the cross-sectional cohort with 154 patients, correlation between the modified (U8) score and clinical disease activity parameters (CDAl and DAS28) was significant but modest $(r=0.3, P=0.03$ and $r=0.4$, $P=0.01)$ respectively. The same was true for the (U $8+2$ score) $(r=$ $0.41, P=0.0001, \quad r=0.4, P=0.005$ ). The $8+1$ (U9 score) gave the best positive correlation with CDAl and DAS28 $(r=0.7, \quad P<0.001, \quad r=0.6$, $P<0.001)$ respectively.

HAQ was highly correlated with U9 score $(r=0.7, P<0.001)$ and moderately correlated with U8+2 score $(r=0.3, P=0.05)$ and not correlated with the modified 8 score.
Conclusion: The U9 score gave the best correlation with disease activity parameters. It is simple and applicable and gives a high degree of flexibility to the sonographer according to the clinical picture.

\section{REFERENCES:}

[1] A novel 8-joint ultrasound score is useful in daily practice for rheumatoid arthritis. Modern Rheumatology 25(3).

DOI: $10.3109 / 14397595.2014 .974305$

Disclosure of Interests: None declared

DOI: 10.1136/annrheumdis-2019-eular.2505

\section{FRI0625 ASSESSING SYNOVITIS IN PATIENTS WITH RHEUMATOID ARTHRITIS BY ULTRASOUND - AN AGREEMENT STUDY EXPLORING THE MOST ACTIVE SIDE}

Lene Terslev ${ }^{1,2}$, Robin Christensen ${ }^{2,3}$, Anna-Birgitte Aga ${ }^{4}$, Joe Sexton $^{4}$, Espen A. Haavardsholm ${ }^{4}$, Hilde Berner Hammer ${ }^{4} .{ }^{1}$ Rigshospitalet-Glostrup, Center for Rheumatology and Spine Diseases, Copenhagen, Denmark; ${ }^{2}$ Frederiksberg Hospital, parker Institute, Copenhagen, Denmark; ${ }^{3}$ Odense University Hospital, Rheumatology, Odense, Denmark; ${ }^{4}$ Diakonhjemmet hospital, Rheumatology, Oslo, Norway

Background: Though ultrasound examination of all RA patients - if offered a very tight clinical control - may not be necessary for obtaining clinical remission $(1,2)$, there are still patients where ultrasound may have a role in monitoring disease activity. Scoring synovitis unilaterally will by far reduce the examination time, however, no consensus exists on how to choose the side to be examined and if one side per se is always the most inflamed side.

Objectives: To assess ultrasound (US) inflammation and sensitivity to change in hands, aiming to identify if the right hand, the dominant hand, or the hand with more clinically swollen joints (SwJ) is per se the most inflamed and more sensitive to change, and hence the preferred side for unilateral scoring of synovitis by US in rheumatoid arthritis (RA) patients. Methods: This is an agreement study exploring the impact on US scoring methods in a longitudinal study of early RA (ARCTIC trial, $n=230$ ) and established RA (ULRABIT trial, $n=212$ ) patients initiating conventional and biological Disease Modifying Anti-Rheumatic Drugs, respectively. Tender and swollen joint count for 28 joints (TJC28 and SJC28) and C-reactive protein (CRP $\mathrm{mg} / \mathrm{L}$ ) were obtained. Using the hands as model, bilateral MCP 1-5, PIP $2+3$ and wrists were evaluated by US using a $0-3$ scoring system for grey-scale (GS) and power Doppler (PD) US according to the atlas by Hammer et al. (3) GS sum score, PD sum score and global synovitis score (GLOESS) were calculated for each hand (0-30). According to our prespecified protocol a reasonable equivalence margin in this study (agreement between groups) was defined to correspond to a $95 \%$ Confidence Interval around the observed paired mean difference: -2.99 to +2.99 .

\begin{tabular}{|c|c|c|c|c|c|c|}
\hline \multicolumn{7}{|c|}{ 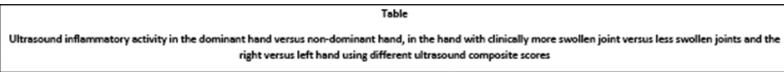 } \\
\hline \multicolumn{4}{|c|}{ Bosetine } & \multicolumn{3}{|c|}{ Change values from beseline to 3 monts } \\
\hline & os swossocore $(0-30)$ & 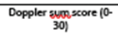 & GLoEss $[0.30]$ & $\triangle G S$ sussecore $[0 .-30]$ & $\begin{array}{l}\Delta D \text { opplet funsecore } \\
(0,30)\end{array}$ & $\begin{array}{l}\Delta \text { GLoess }[0- \\
30]\end{array}$ \\
\hline & $\operatorname{Mes}(95 \times C)$ & $\operatorname{Mean}(95 \% \mathrm{C})$ & $\operatorname{Mesen}(95 \% 0)$ & $\operatorname{Men}(95 \times d)$ & $\operatorname{Meon}(95 \% \mathrm{O})$ & $\operatorname{Mean}(95 \% 0)$ \\
\hline \multicolumn{7}{|c|}{ 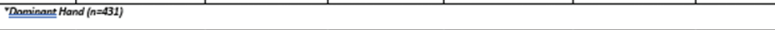 } \\
\hline Dominant & $\begin{array}{l}7.7 .75 \\
0.0980 .00)\end{array}$ & $=\begin{array}{l}4.31 \\
\{42650.35\}\end{array}$ & $=\frac{8.07}{(0.3960 .75)}$ & $=\frac{-3.11}{[-3.355(20-2.57)}$ & 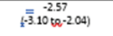 & 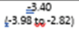 \\
\hline $\begin{array}{l}\text { Nonn } \\
\text { Damionat } \\
\end{array}$ & $\begin{array}{l}7.06 \\
\{5.41207 .72\}\end{array}$ & 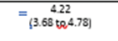 & 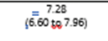 & $=\frac{-3.12}{(2-3.6688 .258)}$ & $\begin{array}{ll}-2.35 \\
\bar{k}-288 \\
(6-1.182)\end{array}$ & $\begin{cases}-3.29 \\
\{-3.35,58-271\}\end{cases}$ \\
\hline Qittecesses & 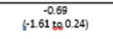 & $\begin{array}{l}-0.58 \\
\{-13560.20\}\end{array}$ & 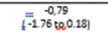 & $(-0.7600 .00 .75 \mid$ & 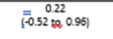 & $\begin{array}{l}0.11 \\
1-0.7050 .0 .921\end{array}$ \\
\hline Pyalue & 0.15 & 0.14 & 0.11 & 0.99 & 0.57 & 0.79 \\
\hline \multicolumn{7}{|c|}{ "Clinicel Hand (swollen joints) (n=314) } \\
\hline 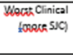 & $=\begin{array}{c}8.51 \\
{[7.8759 .16)}\end{array}$ & 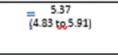 & $=\begin{array}{c}8.33 \\
(8.16599 .50)\end{array}$ & $={ }_{(-4.32: 58-3.25)} \cdot 3$ & 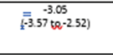 & $\begin{array}{c}-4.06 \\
(1-4.6360-3.49)\end{array}$ \\
\hline $\begin{array}{l}\text { Least Cinical } \\
\text { (ttewess SIC) }\end{array}$ & {$\left[\begin{array}{ll}6.350 \\
{[5.65994)}\end{array}\right.$} & $\{3.1360 .20\}$ & $\left.={ }_{(5.85687 .19}^{6.52}\right)$ & $=\frac{-2.45}{\left[-298_{(20}-1.92\right)}$ & 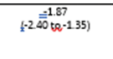 & $\begin{array}{c}-2.64 \\
(-3.2168-20.56)\end{array}$ \\
\hline Difteceoses & 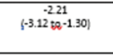 & 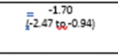 & 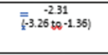 & $=\begin{array}{l}1.34 \\
=0.6052 .08\}\end{array}$ & 10.4177 & $\begin{array}{c}1.43 \\
0.6382 .222 \\
\end{array}$ \\
\hline Pratue & $<.0001$ & $<0001$ & $<.0001$ & 0.0004 & 0.002 & 0.0005 \\
\hline \multicolumn{7}{|c|}{ Hand sidk (n=437) } \\
\hline Right side & $\begin{array}{l}7.78 \\
(7.12 \times 8.44)\end{array}$ & 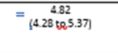 & $\begin{array}{l}=812 \\
=0.468850)\end{array}$ & $\begin{array}{c}\cdot 3.19 \\
(-3.373 \mathrm{~s} \cdot-2.65)\end{array}$ & $\begin{array}{c}-2.64 \\
(-3.17(6-2.211)\end{array}$ & $\begin{array}{c}-3.49 \\
(-4.0750-2.91)\end{array}$ \\
\hline betstivat & $\begin{array}{l}7.03 \\
45.37207 .68\}\end{array}$ & $\begin{array}{l}=421 \\
3.689 .76)\end{array}$ & $\begin{array}{l}=723 \\
\langle 6.55807 .91]\end{array}$ & $\begin{array}{c}-3.05 \\
(-3.59 \cdot 50-2.51)\end{array}$ & $\begin{array}{c}-2.28 \\
(-281+0 .-175)\end{array}$ & $\begin{array}{c}-3.21 \\
(-3.3 .250-2.63)\end{array}$ \\
\hline Quterecoses & $-0.75{ }_{1.63-0.18)}=$ & $\left.{ }_{1.36-0.16)}^{-0.61}\right]^{-}$ & ${ }_{1.05-0.085}=$ & $\begin{array}{c}0.14 \\
\left(-0.611_{80.89}\right)\end{array}$ & $\begin{array}{c}0.36 \\
(-0.3862110)\end{array}$ & $\begin{array}{c}0.29 \\
1-052(62.099)\end{array}$ \\
\hline Ravalua & 0.11 & 0.12 & 0.07 & 0.71 & 0.34 & 0.49 \\
\hline
\end{tabular}

effect, and the patient-ID was applied as a random effect 
Results: 437 RA patients were included in the current analysis; $71 \%$ women, 79\% anti-CCP pos, 71\% RF pos, median(IQR) age 54(42-62) years, CRP 7(3-16), SJC28 5(3-26) and TJC28 6(2-28). The median (IQR) PD sum score was 3(0-7) for right hand and 2(0-5) for left hand, GS sum score was 5(2-9) for both hands, and GLOESS was 5(2-10) for right hand and 5(2-9) for left hand. The average ultrasound measured inflammation at baseline and 3 months follow-up are shown in the table. The hands with more vs fewer SwJ had more inflammation at baseline for all sum scores, all $\mathrm{p}<.0001)$ ) and had a greater change for all sum scores at 3 months follow-up (all $\mathrm{p}<0.0005)$ ). No such differences were found between the dominant vs non-dominant or the right vs left hands at any time points - see table.Conclusion: Based on this study, assessment of the dominant hand is not superior to the non-dominant hand in inflammatory activity evaluated by US. The hand with clinically more SwJ at baseline is likely to have more active inflammation according to GS, Doppler and GLOESS sum scores and exhibit a greater change, and is potentially the best choice for unilateral US scoring systems.

\section{REFERENCES:}

[1] Dale J, Stirling A, Zhang R, Purves D, Foley J, Sambrook M, et al. Targeting ultrasound remission in early rheumatoid arthritis: the results of the TaSER study, a randomised clinical trial. Ann Rheum Dis. 2016;75:104350

[2] Haavardsholm EA, Aga AB, Olsen IC, Lillegraven S, Hammer HB, Uhlig T, et al. Ultrasound in management of rheumatoid arthritis: ARCTIC randomised controlled strategy trial. BMJ. 2016;354:14205.

[3] Hammer HB, Bolton-King P, Bakkeheim V, Berg TH, Sundt E, Kongtorp $A K$, et al. Examination of intra and interrater reliability with a new ultrasonographic reference atlas for scoring of synovitis in patients with rheumatoid arthritis. Ann Rheum Dis. 2011;70:1995-8.

Disclosure of Interests: Lene Terslev Speakers bureau: Speakers fee from : Roche, Novartis, Pfizer, MSD, BMS, Celgene, Robin Christensen Grant/research support from: AbbVie Inc, and the Oak Foundation, Speak ers bureau: Roche, Anna-Birgitte Aga Consultant for: UCB, AbbVie, and Pfizer, Paid instructor for: UCB, Joe Sexton: None declared, Espen A Haavardsholm Grant/research support from: research funding from Pfizer, UCB, Roche, MSD, and AbbVie., Hilde Berner Hammer Speakers bureau: speakers fee from AbbVie, Bristol-Myers Squibb, Roche, UCB Pharma and Pfizer DOI: 10.1136/annrheumdis-2019-eular.2837

\section{FRI0626 DIFFICULTIES WITH MAKING A FIST IN PATIENTS WITH CLINICALLY SUSPECT ARTHRALGIA; AN EARLY PHENOMENON PREDICTIVE FOR RA THAT IS RELATED TO MRI-DETECTED TENOSYNOVITIS}

Fenne Wouters ${ }^{1}$, Florus van der Giesen ${ }^{1}$, Xanthe Matthijssen ${ }^{1}$,

Ellis Niemantsverdriet ${ }^{1}$, Annette van der Helm - van Mil ${ }^{1,2}$. ${ }^{1}$ Leiden University

Medical Centre, Rheumatology, Leiden, Netherlands; ${ }^{2}$ Erasmus University Medical Centre, Rheumatology, Rotterdam, Netherlands

Background: Difficulties with making a fist in patients presenting with recent-onset arthralgia of small joints, in whom there is no clinically detectable arthritis, is often considered a risk factor for the development of inflammatory arthritis. The fact that rheumatologists consider difficulties with making a fist a feature of imminent Rheumatoid Arthritis (RA) is also reflected by this sign being incorporated in the EULAR definition of arthralgia suspicious for progression to RA. However, to date there is little comprehension on its predictive value and underlying cause in patients with recent-onset arthralgia.

Objectives: This study was performed to 1) determine if difficulties making a fist is indeed predictive for the development of clinical arthritis, and 2) evaluate if this sign is associated with subclinical joint inflammation, detected by magnetic resonance imaging (MRI).

Methods: 566 patients presenting with recent-onset $(<1$ year) arthralgia of small joints that were consecutively included in the Clinically Suspect Arthralgia (CSA) cohort were studied. At baseline the ability to completely close the fist (all fingertips touching the palm) was assessed at physical examination. Additionally, contrast-enhanced $1.5 \mathrm{~T} \mathrm{MRI}$ of wrist, $2^{\text {nd }}-5^{\text {th }}$ metacarpophalangeal (MCP) and $1^{\text {st }}-5^{\text {th }}$ metatarsophalangeal (MTP) joints was performed. MRIs were scored for synovitis, bone marrow edema (BME) and tenosynovitis in line with the RAMRIS. MRI-detected subclinical inflammation was considered present if it was more than observed in symptom-free controls from the general population in the same age-category $(n=193)$. Patients were followed on the development of clinically detectable inflammatory arthritis identified at joint examination (median follow-up 19 months); none of the patients received DMARDs before the development of clinical arthritis. $\chi^{2}$ tests, logistic and Cox proportional hazards regression were used as appropriate.

Results: At first presentation $12 \%$ of CSA-patients had difficulties making a fist with one or both hands. Having difficulties making a fist was predictive for development of clinical arthritis in univariable analysis (HR 2.47 $(95 \% \mathrm{Cl} 1.46-4.19))$ and in multivariable analysis (HR $2.16(1.25-3.74)$ corrected for age, CRP, ACPA and MRI-detected subclinical inflammation). Patients with difficulties making a fist had significantly more often MCP tenosynovitis (flexor tenosynovitis and extensor peritendinitis combined) than patients who did not experience these problems (42\% versus $16 \%$, $\mathrm{p}<0.001)$. The main difference was seen in MCP flexor tenosynovitis $(39 \%$ versus $10 \%, \quad \mathrm{p}<0.001)$. MCP flexor tenosynovitis was significantly associated with difficulties making a fist in univariable (OR $5.6(95 \% \mathrm{Cl}$ 3.2-9.9)), and multivariable regression (OR 5.7 (3.2-10.2) corrected for extensor peritendinitis, synovitis and BME in MCP joints). Extensor peritendinitis, synovitis and BME in MCP joints were not associated with difficulties making a fist (multivariable OR 0.7 (0.2-2.1), $0.99(0.5-2.1)$ and 1.6 (0.7-4.1), respectively).

Conclusion: Difficulties making a fist in patients with CSA is predictive for future inflammatory arthritis development. This sign is presumably caused by MCP flexor tenosynovitis in a significant proportion of patients. Disclosure of Interests: : Fenne Wouters: None declared, Florus van de Giesen: None declared, Xanthe Matthijssen: None declared, Ellis Niemantsverdriet: None declared, Annette van der Helm - van Mil Grant/ research support from: The research leading to these results has received funding from the European Research Council (ERC) under the European Union's Horizon 2020 research and innovation programme (Starting grant, agreement No 714312) and from the Dutch Arthritis Foundation.

The funding source had no role in the design and conduct of the study. DOI: 10.1136/annrheumdis-2019-eular.3003

\section{FRI0627 DOES ADDING AN US EXAMINATION OF SHOULDERS, TO A ROUTINE DAS-28 SCORE, IMPROVE ACCURACY OF DISEASE ACTIVITY SCORES AND DISEASE STATUS? RESULTS OF A SINGLE CENTRE PILOT STUDY}

Qasim Akram ${ }^{1}$, Lara Valor ${ }^{2}$, lustina Janta ${ }^{3}$, Juan Carlos Nieto ${ }^{3}$, Letitia Garcia ${ }^{3}$, Belen Serrano ${ }^{3}$, Teresa Pedrosa ${ }^{3}$, Francisco J. López-Longo ${ }^{3}$, Indalecio Monteagudo Sáez ${ }^{3}$, Esperanza Naredo ${ }^{4} .{ }^{1}$ The Pennine Acute Hospitals NHS Trust, Rheumatology, Manchester, United Kingdom; ${ }^{2}$ Gregorio Marañón, Madrid, Spain; ${ }^{3}$ Gregorio Marañón Hospital, Madrid, Spain; ${ }^{4}$ Hospital Universitario Fundación Jiménez Díaz, Madrid, Spain

Background: The DAS28 forms the mainstay of current RA and othe chronic inflammatory arthritis (CIA) [i.e. peripheral spondyloarthritis (SpA)] management in clinical practice. DAS28 has certain limitations. Some joints especially the shoulders are difficult to evaluate correctly using this method. The shoulder is deep and highly affected by rotator cuff tendon lesions either due to degenerative or inflammatory arthritis This structural damage can produce pain and swelling. A swollen shoulder joint can be difficult to palpate by physical examination. Using a clinical approach can be inaccurate to ascertain whether shoulder involvement is actually due to true RA-derived inflammatory activity or other degenerative or structural causes.

Objectives: To investigate the added value of adding a US assessment of shoulders to DAS28 scores and on disease activity status, in patients with CIA (RA or peripheral SpA) in either disease remission or low disease states who had shoulder pain.

Methods: Patients were recruited prospectively over a 3-month period Each patient had a standard DAS28 performed followed by a forma physical shoulder examination, of both shoulders, including testing active and passive range of movements. A complete US examination of both shoulders was carried out by a rheumatologist experienced in this technique. All patients were examined using the same real-time US machine (Esaote MyLab Twice) using a linear probe, 3-13 MHz frequency and $57 \%$ gain. The original DAS28 was recalculated (i.e. US-modified DAS28) according to the presence/absence of inflammatory findings on shoulder US

Results: Thirty-eight patients $[82 \%$ females; mean ( \pm SD) age 60.3 (11.96) years] were included. In 33 out of 38 (87\% [Cl95\%: $76-98 \%$ ]) patients the original DAS28 was greater than the US-modified DAS28. This percentage was significantly greater than $50 \%(p<0.001)$. The mean $\pm S D$ reduction of DAS28 in those patients who showed DAS28 decrease was $0.73 \pm 0.39$ units. Twenty-five patients $(65.8 \%)$ maintained the same disease activity status with original DAS28 and US-modified 